the open sea, and Mya arenaria, usually found in mud flats. This latter is universal along the shores of the Western Hemisphere as far south as New York and in the Fastern Hemisphere as far south as Rochelle and between the thirtieth and fortieth degrees of latitude, and is also common on many parts of the British coast, about low-water mark and chiefly in tidal estuaries where there is an admixture of fresh and sea water. The body of the clam is fleshy and of a yellowish-white colour and is provided with a "foot" with which it penetrates the sand or mud, the "foot" assuming various shapes for this purpose. In addition, the clam has also two syphonic tubes which when the animal is at rest are drawn down nearly into the shell. When active these syphonic tubes are protruded, one continuously drawing in and the other pouring out a stream of water, the food particles in the water being retained in the body. The shells are oval and of an ashy grey colour, a good specimen measuring about two and a half inches by five inches; those referred to in this article measured about one and a half inches by two and three-quarter inches. They are usually jound buried about six inches deep in the mud but retire deeper than this when the tide is out. In Europe, Asia, and America they are used as food and relished by certain classes and are usually sold in a boiled condition. In the United States the clam is more important from an economical point of view than the oyster, large quantities being sold annually in Boston market as food for man and many more are salted and used as bait for fish. An excellent article on Myidæ is given in "British Conchology," Vol. III, by J. G. Jeffreys, F.R S., from which most of the information concerning these shell-fish has been obtained.

The outbreak to which this article refers occurred in the Maldon rural district. On Oct. 20th, 19C6, two men living in Heybridge were notified to be suffering from typhoid fever. The cases were immediately visited and on inquiries being made the fact was nltimately elicited that both men had partaken of some clams which were sold by a hawker in the bar of a local public house on Sept. 29 th. It was unfortunately impossible to ascertain the names of all the men present in the bar when the clams were sold. Nerer. theless, names and addresses of five men, in addition to the two notified, were obtained, all of whom had eaten varying quantities. In each instance ill effects had been produced; one man was found to be suffering from what was considered to be a low type of influenza but he was notified later to be suffering from typhoid fever; the second had been seized with diarrhcea and vomiting within two hours of eating the clams, the third had had a so-called bilions attack, and the remaining two had suffered from sickness and diar rhoea to such an extent as to prevent them from following their usual occupation for a few days Thus, out of seven persons known to have partaken of the clams on this particular occasion three afterwards suffered from typhoid fever and the others from diarrhœa and sickness. Fortunately none of the cases have proved fatal.

The clams in question were obtained from the mud on the banks of the tidal estuary of the Blackwater in close proximity to the outfall sewer of the town of Maldon. They were stated to have been thoroughly cleaned and boiled but the boiling probably consisted in placing the clams in boiling water for a few seconds until the shells opened. The price charged by the hawker was four a penny and it is a significant fact that the men who consumed the largest quantitiesnamely, four pennyworth each-contracted typhoid fever. Unfortunately, I was unable to obtain a sample of these particular clams, but others from the same source were obtained and submitted to a bacteriological examination. The method of examination was as follows :-

1. Three clams, which had not been subjected to boiling, were taken and opened with a sterile knife and the bodies were cut up into small pieces and emptied together with the liquid contents from the shells into a sterile mortar. 900 cubic centimetres of sterile water were added to this the resulting mixture being thoroughly stirred and ground up. A dilution was thus obtained of which 300 cubic centimetres corresponded to one clam. From this the following amounts-namely, $\frac{1}{2}$ cubic centimetre, 1 cubic centimetre, 3 cubic centimetres, and 10 cubic centimetres, which corre-

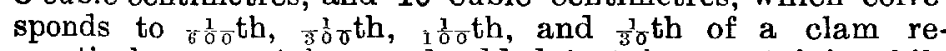
spectively, were taken and added to tubes containing bile salt glucose broth. Acid and gas were formed in each instance after 24 hours' incubation. Plates of bile salt lactose agar containing neutral red were made from these broths and the red colonies showing a baze were further examined and the subsequent cultural reactions corresponded with those obtained with bacillus coli communis. On incubating anaerobically in milk the bacillus enteritidis sporogenes was found to be present in ${ }^{1} 0_{0}$ th of a clam.

2. Three clams were well boiled in water for 15 minutes, the bodies were cut through, and one cubic centimetre of the liquid obtained therefrom was added to a tube containing bile salt glucose broth. Acid and gas were formed and all the reactions of the bacillus coli communis were obtained.

The resuits of this examination proved the clams to be grossly polluted with sewage, inasmuch as the bacillus coli communis could be detected in $\frac{1}{6} \mathrm{tb}$, and the bacillus enteritidis sporgenes in $\frac{1}{3} \frac{1}{0}$ th part of a clam. It is especially noteworthy that even after boiling for 15 minutes the bacillus coli communis could be recovered from the bodies of the clams. The presence of bacillus typhosus could not be demonstrated, though a few suspicious growths were obtained on Drigalski and Conradi medium. These, however, did not correspond with the confirmatory tests of this organism. The fact that even 15 minutes' boiling failed to sterilise the clams is interesting, since it proves that shell-fish from a grossly polluted source cannot be rendered safe for human consumption even when buled so lorg as to render them hard and indigestible. Shell-fish, such as these, if boiled for a shorter time would be much more dangerous, as more of the bacteria present therein would escape destruction.

I am much indebted to Dr. J. C. Thresh, medical officer of health of the county of Essex, for his kindness in allowing me to publish the details of this outbreak.

Chelmsford.

\section{ABSENCE OF THE UTERUS IN THREE SISTERS AND IN TWO COUSINS.}

By L. NAPOLEON BOSTON, A.M., M.D.,

ADJUNCT PROFESSOR OF MEDICINE AT THE MEDICO-CHIRURGICAI COLLEGE; PHYSICIAN TO PHILADELPHIA HOSPITAL; AND DIRECTOR OF LABORATORIES FOR CLINICAL RESEARCH AT THE AMERICAN HOSPITAL FOR DISEASIS OF THE STOMACH.

THIS report of a family consisting of three sisters, the oldest 33 and the youngest 22 years of age, is offered largely as a matter of anatomical anomaly, although it is of material importance from a medico-legal standpoint since one of this trio married at the age of 25 years, and consf quently became a subject of the divorce courts. The development of the breasts and the other changes known to puberty were experienced, except menstruation. The breasts and nipples were normally developed in each woman. Sentiment, sexual appetite, and sexual sensation were normal in each of these women.

Absence of the uterus is not infrequent judging from the number of cases which I have been able to collect from the literature. Lieutaud ${ }^{1}$ bas reported the case of a young woman where there was absence of the uterus, ovaries, and Fallopian tubes. Richerand ${ }^{2}$ cites a similar case, both of which cases were based upon necropsy findings. From reported cases I find that absence of the uterus together with absence or deformity of the vagina is far more common than is simply absence of the uterus, and there is also apt to be associated deformity of the bladder, kidneys, clitoris, and labia. In striking contrast with these commoner deformities, the vagina, labia, and clitoris were normal in each of my cases and the hymen, or evidence of its having existed, was present twice. Phillips ${ }^{3}$ reports an instance of two sisters, both of whom married and in whom there was a congenital absence of the uterus. Phillips's cases compare very closely to the three sisters, the subject of this paper. Sedgwick ${ }^{4}$ cites the instance of another family where there was absence of the uterus in three of five sisters. That there was no deformity of the vagina and probably no sexual abnormality in Sedgwick's cases is evidenced through the fact that two of these three sisters were married twice. Sedgwick discusses at length the question of heredity in connexion with these malformities, but in my series of cases I was unable to gather any evidence of heredity.

1 Dictionnaire des Sciences Médicales, vol. 1x., 1812.

3 Brit. Med. Jour., June 18th, 1870

4 Medico-Chirurgical Review, London, July, 1863. 
Family history. - The father and mother were born in Ireland. The father died at the age of 37 years from pneumonia. The father had four sisters, all of whom came to the United States, where they married and reared large families. The paternal grandmother reared a family of 14 children and each of her seven sisters married and bore children. The mother, now 64 years old, married at the age of 25 years, bore these three daughters, and is exceptionally well preserved. There is no history of any of her sisters or relatives having been afllicted with abnormality of the organs of reproduction. The great-grandmother had four sisters who married and each bore children.

CASE 1.-Miss X., aged 22 years, complexion fair, eyes blue, hair and eyebrows heavy brown, features perfect (decidedly feminine), height 5 feet $9 \frac{1}{2}$ inches, weight 136 pounds, a clerk, was born in Philadelphia. She had always enjoyed perfect health, except for an attack of diphtheria at the age of 17 years. She first consulted me for cardiac palpitation and general weakness ; at which time the diagnosis was secondary anæmia, probably induced by overwork and too close confinement. Following treatment her erpthrocytes increased from $3,200,000$ to $4,600,000$ per cubic millimetre; the hæmoglobin from 72 to 88 per cent.; while the leucocytes remained at approximately 10,000 per cubio millimetre. I was informed that menstruation had never been established and was further told that two older sisters, one 33 and one 27 years of age, had likewise never menstruated. Six months later Miss X. again consulted me for secondary anæmia which yielded promptly to treatment. Both this woman and her sister, Case 2 , experienced periodic attacks of tenderness of the breasts, but I was unable to get any definite history as to the intervals between such attacks. Case 3 noticed her breasts to be unusually sensitive for some months after her marriage but could not recall that these attacks were at or near the time she vomited blood. In $1904 \mathrm{I}$ suggested to the mother that a vaginal examination should be made, wbich was accordingly done with the following findings. There were but few light hairs surmounting the mons Veneris and the labia were normal. The clitoris was of normal size and appearance and possessed the sensa tion normal to this organ. The mucous membrane of the vulva and vagina was lubricated with a mucous exudate and was normal in every respect. The vagina permitted the introduction of three fingers for its entire length of three and three-quarter inches. At a point corresponding to the normal position of the cervix the vagina terminated as a closed sac, but the calibre of the vaginal canal remained uniform throughout. By bimanual examination it was impossible to detect any uterus, nor was it possible to induce pain or to elicit tenderness by firm pressure in the ovarian regions. Vaginal examination by the use of a speculum showed the vagina to terminate abruptly. There was no intimation of a cervix uteri, nor were there indentations, scars, or fissures in the vaginal wall.

CASE 2.-Miss J., aged 27 years, complexion fair, brunette, features fine and decidedly feminine, temperament hysterical, height 5 feet 4 inches, weight 120 pounds, occupation housework, was born near Philadelphia. She had the ordinary diseases of childhood, including scarlet fever. Her health had been perfect until the age of 23 years, since which time she had suffered at intervals from facial neuralgia. Most interesting in connexion with this case is that at

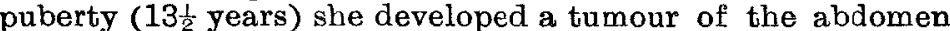
which grew steadily for a period of two and a half years. Both the patient and her family claimed that her abdomen became so markedly distended that they consulted three physicians, each of whom made a vaginal examination and reported that they were unable to find the cervix uteri. The tumour developed mostly on the right side of the abdomen and, according to the mother's description, reached to the lower border of the right costal margin. Once each month during the existence of this tumour she had profuse hæmorrhages from the nose and upon three occasions she vomited a small quantity of blood. At the age of 16 years she noticed that her abdomen was decreasing in size and by the twentieth year the tumour had apparently disappeared. There had never been vaginal hæmorrhage. Vaginal exami nation revealed essentially the same conditions described in the report of Case 1 of this series, except that the hair of the pubic region was heavy and black and the labia majora were decidedly thicker (hypertrophied). The length of the vagina was two and five-eighth inches. The bymen was intact and displayed a central opening.

CASE 3.-Mrs. K., aged 33 years, brunette, a widow, married at the age of 25 years, height 5 feet $5 \frac{1}{2}$ inches ; her weight at the time of marriage was 120 pounds; and her present weight was 234 pounds. She had enjoyed good health, suffering only from the diseases of childhood. At puberty she experienced most of the changes common to that age, and had periodic attacks of nose-bleeding until the age of 22 years, tie nasal bæmorrbages occurring about every 26 days, and at this time she suffered from temporary enlargement of the glands of the neck, particularly those below the angle of the jaw, and from a mild sore throat. During the first year of her married life she vomited blood twice and gained 22 pounds in weight. She had never bad bleeding from the vagina and stated that her sexual relations were perfectly congenial. Vaginal examination disclosed practically the same condition as described under Case 1, except there was no evidence of a previously existing hymen, the vagina was four and one-eighth inches long, and the pabic region was covered with black hair.

CASES 4 AND 5.-I have learned through the courtesy of the late Dr. H. C. Bacon of two women, about the age of 40 years, cousins, now married, and neither of whom ever menstruated. These women were decidedly feminine in stature and in sentiment, while in both sexual congress was accompanied by the normal sensations. In both of Dr. Bacon's unreported cases vaginal examination showed the external genitalia and the vagina to be normal and an absence of the uterus.

Philadelphia.

\section{Clinital oflotes:}

\section{MEDICAL, SURGICAL, OBSTETRICAL, AND THERAPEUTICAL.}

\section{NOTE ON A CASE OF RUPTURE OF THE ROOT OF THE LUNG WITHOUT INJURY TO THE CHEST WALL.}

By Helen Chambers, M.B., B.S. Lond., CLINICAL PATHOLOGIST TO THE ROYAL FREE HOSPITAL.

WiтH reference to the case of extensive rupture of the trachea with complete detachment of the left bronchus published in THE LANCET of Dec. 1st, 1906, p. 1509, the following case of a somewhat similar injury may be of interest.

A well-nourished girl, aged five years, whilst crossing the road and carrying another child slipped and fell forwards. The wheel of a large four wheeled van passed over her back. She was brought in dead to the casualty department of the Royal Free Hospital. At the post-mortem examination superficial abrasions of the skin and slight bruising on the back suggested that the wheel had passed obliquely from the right shoulder downwards to the left, crossing the spine at the level of the twelfth dorsal vertebra. There were no other external signs of injury except a few abrasions on the upper limbs and in the lett temporal region. There was no surgical emphysema or pneumothorax. The left pleural cavity contained eight ounces of blood. The root. of the left lung had been torn across. The tear resembled an incised wound and extended through the main bronchus and vessels, including all the structures of the root except a thin strand of pleura and a nerve. The lung was lying almost free in the pleural cavity. The left lurg showed a laceration in the upper lobe parallel to, and about one inch above, its lower border. It was half an inch deep at the upper end and at the lower end extended completely through the lung substarce, exposing the pleura on the posterior surface. The tissues at the margins of the laceration showed only slight bruising. The right pleural cavity contained three and a half ounces of blood. The root of the right lung was uninjured. The apex of this lung was nearly completely torn off, being attached posteriorly by a strand of lung tissue. The rest of the lung showed some bruising. Both lungs were of normal size. The trachea was uninjured but contained some blood-stained fluid. There was slight extravasation of blood in the posterior mediastinum. i'he pericardium was normal. The heart was empty and firmly contracted. The left ventricle was slightly bruised on the anterior surface. The spleen 